International Journal of Linguistics, Literature and Translation

ISSN: 2617-0299 (Online); ISSN: 2708-0099 (Print)

DOI: 10.32996/ijltt

Journal Homepage: www.al-kindipublisher.com/index.php/ijltt

\title{
An Investigation of Using Audio-Visual Aids in the EFL Classes in Libya: A Case Study of Kufrah Secondary Schools
}

\author{
Ahmed Sanoussi Himeda Al Jawad 8 (D) $\square$ \\ Assistant Professor, Department of English Language, Faculty of Arts \& Science Kufrah, Benghazi University, Libya \\ $\triangle$ Corresponding Author: Ahmed Sanoussi Himeda Al Jawad, E-mail: ahmed.jawad@uob.edu.ly
}

ARTICLE INFORMATION

Received: January 08, 2021

Accepted: March 02, 2021

Volume: 4

Issue: 3

DOI: $10.32996 /$ ijllt.2021.4.3.22

\section{KEYWORDS}

Teaching EFL, Secondary Schools, Audio Visual Aids, Libyan Context

\section{ABSTRACT}

This study investigates the use of audio-visual aids in the EFL classes in Libyan secondary schools. Specifically, it aims to determine how audio-visual aids could work as an excellent motivational instrument for teachers and students in Kufrah secondary schools. Two sets of questionnaires were administered to teachers and students to clarify the needed information. Kufrah secondary schools were chosen for the survey study. 80 students, and 20 teachers were randomly selected. Through the questionnaires made by the researcher, the data was collected, organized and analysed using statistical techniques like percentages. The results of the study revealed that the use of audio-visual aids to develop EFL students seemed to be effective, as indicated by the teachers and students. The results also showed fewer teacher training opportunities in schools and restricted administrative support. The researcher recommends appropriate teacher training, adequate audio-visual equipment and material, and needed administrative support to ensure the optimum use of audio-visual aids, ensuring the learner's maximum benefit.

\section{Introduction}

Education is necessary for all. There is no doubt that, without education, no one can lead a good life. Teaching and learning are important elements of education. The teachers use different methods and materials to teach their students to make learning effective. Over time, different methods and techniques have been introduced in education. The teachers use different aids to make teaching effective. The teaching aids arouse learners' interest and help teachers elucidate concepts easily. There is no doubt that audio-visual aids are those educational aids used in the EFL classroom to encourage the learning process in teaching, make it easier and interesting. The material such as charts, maps, models, film strip, projectors, radio, television etc. is called instructional aids (Rather, 2004)".

"Audio-visual aids provide the learners with realistic experience, which captures their attention and helps understand the historical phenomena. They appeal to the mind through the visual-auditory senses. (Jain, 2004) ". There is a famous proverb "one seeing is worth, a hundred words it is a fact that we receive knowledge through our senses. There is another proverb that if we hear, we forget if we see we remember, and if we do something, we know it"; therefore, it means that the use of audio-visual aids makes the teaching and learning process more operative. As Kishore (2003) said "audio-visual aids stimulated thinking and understanding". The use of audio-visual aids in teaching and learning process has multifarious values (Mohanty, 2001)". "The audio-visual aids provide opportunities for speakers to make a more professional and consistent presentation. The teaching profession is filled with countless opportunities to enrich students' academic life; while some educational concepts and goals will be easy for students to understand, others require you to think creatively to ensure important learning goals are achieved.

\subsection{Statement of the Problem}

"Good education policies are supported by well-designed programmes implemented inefficiently by the government and the authorities of educational institutions. Thus, learners are not sufficiently exposed to those experiences that will ensure the full development of their existence. At present, we live in a global village. Around the globe, the latest and most complex technology

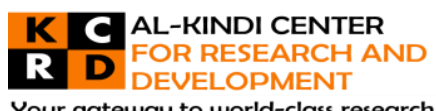

Your gateway to world-class research

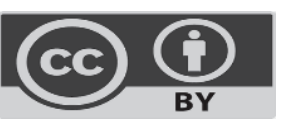

Published by Al-Kindi Center for Research and Development, United Kingdom. Copyright (c) the author(s). This open access article is distributed under a Creative Commons Attribution (CC-BY) 4.0 license 
is the field of information and communication technology. The growth in internet technology and its application in education have led to a major transformation globally. The use of audio-visual aids will make teaching and learning more efficient, effective and results-oriented by providing ways to exchange ideas and information. The development level in any society is usually determined by the quality and quantity of knowledge in the various areas of human activity available to and acquired by the citizens. Knowledge is acquired and maintained through an effective information and communication system based on the level of technology achieved, and children in any country who fail to use and master new technologies will certainly lack behind".

"However, there are many restrictions in delivering audio-visual aids to the right people at the right time. In countries such as Libya, there is often a deficiency of qualified teachers and a lack of funds. The rapid changes that have taken place worldwide pose a challenge to the education sector. There is a need to enrich the current secondary schools which audio-visual aids for effective teaching and learning process".

\subsection{Questions of the Study}

This study seeks to find answers to the following research questions:

a. Are audio-visual aids used in Kufrah secondary schools?

b. If yes, how much are they beneficial?

c. What are the perspectives of EFL teachers about using audio-visual aids?

d. What are the perspectives of EFL students about using audio-visual aids?

\subsection{The Aims of the Study}

The aims of this study are as follows:

a. To discover the kind of audio-visual aids that EFL teachers use in Kufrah secondary schools.

b. To investigate how the audio-visual aids could work as a good motivational tool for EFL teachers and students in Kufrah secondary schools.

c. To evaluate student's point-of-view towards using audio-visual aids in Kufrah secondary schools.

d. To evaluate EFL teachers' point-of-view using audio-visual aids in Kufrah secondary schools.

\subsection{Limitations of the Study}

The study is limited to the secondary schools in Kufrah; nevertheless, the study outcomes, just like any other study, can be used to rectify the hindrances in Libyan secondary schools. The study is also restricted to audio-visual aids in teaching and learning processes, their impact and capabilities in facilitating the flow of information between the teacher and the students. The writer has chosen the academic year (2017/2018) as a reasonable time to apply this study. The study is about the use of audio-visual aids in Libyan secondary schools.

\subsection{The Importance of the Study}

This study is essential as it investigates the teachers and students' improvement by using audio-visual aids. Many of them might not be well aware of the effectiveness of these. However, this paper will provide EFL teachers with specific language teaching procedures which they can use in their classrooms to ameliorate learners' performance. It is expected that the results of the study will help EFL teachers and students to know better about the impact of using audio-visual aids in Libyan secondary schools. As a result, this study will be a future guideline for the EFL teachers regarding the issue.

\section{Literature Review \\ Definition of Audio-Visual Aids}

a. Audio Aids

According to Subathra (2012), "in the process of learning English language hearing aids like cassettes and recorders were commonly in use. Such aids of teaching aids effectively improved the students' phonetics, pronunciation, and spoken English.

\section{b. Visual aids}

Other modern aids of teaching stated by Subathra are visual aids. "Apart from the traditional visual aids like charts, pictures and models that are still in use in the classrooms; there are other modern visual aids which were in use in recent years. These aids include the picture slides, motion pictures and the like". 


\section{c. Audio-visual aids}

Madhuri (2013) states that " the audio-visual aids are tools of record to improve speaking skills that are used several times and more than others. It is where the object picture section and gestures have been systematically used with audio-visual work to elucidate meaning".

Subathra (2012) "emphasizes the best side of audio-visual aids that they made the process of learning has become quite exciting for the students with the audio-visual aids. It helps the students in generating an open mind for learning. At the same time, it develops teamwork among the students as they are required to work in teams for such project-based learning. Within a short period of time, these audio-visual aids gained much popularity and have shown their dominance".

Ahmad (2013) "emphasizes that in audio visual aids, both the listening (ears) and viewing faculties (eyes) are involved. Such aids include television programs, video films, motion pictures, synchronized audio-slide projectors, computers and computer-assisted instructions and so on. Cartoon films are also a useful medium for developing the students".

\section{Audio Visual in language teaching}

According to Anderson (1994), "audio-visual is a series of video media electronic images accompanied by audio elements. Video material has many advantages because the innovative features that can be used to make instructions more appealing to learners (Keller \& Suzuki, 2004)".and also it "can brings the real world into the classroom" (Cakir, 2006, p. 2). Richards and Renandya (2002) state "that a video is an extremely dense medium, one which incorporates a wide variety of visual elements and a great range of audio experiences in addition to spoken language". Meanwhile, Harmer (2001, p. 282) reveals "the reasons why teachers like to use video material to engage students, those are: "seeing language in use" where students could both listen and watch the scene from video; "cross-cultural awareness" which means that students will be aware of the culture of the target language that might be totally different with students" culture; "the power of creation" means students will find enjoyable when they are directed to create their own video. This could provoke their creativity in using audio visual; it can be a source of "motivation" for students using video learn a target language".

Evidently, audio visual is not novel in language teaching. Sometimes, using video in teaching can be monotone if teachers do not know how to maximize using video. To make the video material more effective, some strategies need to be applied. Cakir (2006) presents "techniques to use video to engage the student. They are: freeze-framing and prediction which means during the video played, teacher will press the pause button two to three times, then students will predict what will happen next. Silent viewing refers to playing the video but turning the sound to arouse students" curiosity. Sound on and vision off means the teacher plays audio without visual. Students will guess or play what happens in the movie. Repetition and role-play: Teachers will have students repeat the play using a role play. Reproduction activity refers to retelling what has happened to the video after watching the session. Dubbing activity which means students need to dub the scene from the movie".

\section{Kinds of Audio-Visual Aids}

According to Ahmad (2013), "there are four kinds of audio-visual aids. They are films, television, video and CDs".

\section{1) Films}

Films represent an effective instructional device to cater to the students' attention and create interest and motivation among them towards practical learning. Educational films may be prepared on any content material or any aspect of knowledge and behaviour.

\section{2) Television}

Television is a versatile medium for transmitting education through different programs. It is an exciting means of communication. Useful instructional programs are being telecasted regularly for the student community on television. A teacher should utilize TV programs and make them the basis for discussions on relevant occasions.

\section{3) Video}

Video is a viable aid for effective learning and teaching. Teaching with the help of video is called video-aided instruction. In video-aided instruction, learners 'comprehension is generally tested through a questionnaire, and video is an instructional medium that generates a much more significant amount of interest and enjoyment than the more traditional printed material. 


\section{4) CDs}

Nowadays, educational video-cassettes are easily available in the market. Educational CDs can be prepared on any aspect of the subject matter and curriculum.

From the above, we can see that audio-visual resources are divided into audio visual and audio and visual resources and others with audio-visual resources that can either be in a projected or non-projected form.

\section{The Advantages of Using Audio Visual Aids}

According to Nupur (2012), there are so many advantages of using audio visual aids, such as:

1. Best motivators: They are the best motivators. Students work with more interest and zeal. They are more attentive.

2. Fundamental to verbal instructions: They help reduce verbalism, which is a significant weakness of the schools. They convey the same meaning as words mean. They give clear concepts and thus help to bring accuracy in learning.

3. Clear images: Clear images are formed when we see, hear, touch, taste and smell as our experiences are direct, concrete and more or less permanent. Learning through the senses becomes the most natural and consequently the easiest.

4. Vicarious Experience: Everyone agrees that the first-hand experience is the best type of educative experience, but such an experience cannot always be provided to the pupils, so in some situations, certain substitutes have to be provided. For this, we find a large number of inaccessible objects and phenomenon. For example, all the Indian students cannot be shown the Taj Mahal. In all such cases, audio-visual aids provide us with the best substitutes.

5. Variety: Audio-Visual aids provide variety and provide different tool $s$ in the hands of the teacher.

6. Freedom: The use of audio-visual aids provides various occasions for the pupil to move about, talk, laugh and comment upon. Under such an atmosphere, the students work because they want to work and not because the teacher wants them to work.

\section{Methodology}

This study follows the descriptive-analytical approach. The writer described and then analysed the collected data; this procedure was done by using data collection material drawn from the students and teachers' questionnaires. This approach is suitable for such studies because it always describes and analyses the collected data.

\subsection{Tools of Data Collect}

The tool used for data collection in this study consisted of two sets of questionnaires for EFL teachers and students. The questions are set to suit research questions.

Each questionnaire is comprised of six items related to the research problems stated in the introduction. The first items in both the questionnaires were related to the question 'Are audio-visual aids used in Kufrah secondary schools?'. The second and the fourth items in both the questionnaires were concerned with 'If yes, how much are they beneficial?'. The third, fifth and sixth items in Teacher Questionnaire had relations to the question 'What are the perspectives of EFL teachers about using audio-visual aids?'. The third, fifth and sixth items in Student Questionnaire were connected to 'What are EFL students' perspectives about using audio-visual aids?' It should be noted that the questionnaires contained almost identical items selected in order to compare the views and diversity of the two groups of participants.

\subsection{Data collection and analysis}

The data of this study are collected from $20 \mathrm{EFL}$ teachers as well as from $80 \mathrm{EFL}$ students learning at secondary schools. To take advantage of teachers' responses to the use of audio-visual aids in the EFL class, the writer personally communicated with teachers and asked them to respond to the items in the questionnaire. And to gather students' responses to the use of audio visual aids in their EFL class, the writer received the collaboration of the teachers who administered the questionnaire after explaining the objectives of the study and some initial instructions. Data collected from both EFL teachers and students were then recorded by hand.

\section{Presentation and interpretation of results Teacher's questionnaire}

The teacher's questionnaire consisted of six items related to the teachers' perspectives on the use of audio-visual aids in their English classes. The answers of the 20 teachers to the questionnaire are as follows: 
Discussion of the first question: Do you use audio-visual aids in your EFL classes?

Table (1): Do you use audio-visual aids in EFL classes?

\begin{tabular}{|c|c|c|}
\hline Scale & No of respondents & Percentage (\%) \\
\hline Yes & 07 & $65 \%$ \\
\hline No & 13 & $\mathbf{1 0 0} \%$ \\
\hline Total & $\mathbf{2 0}$ & $\%$ \\
\hline
\end{tabular}

Table 1 shows that 07 out of 20 teachers answered Yes, while 13 teachers answered No. In other words, 35\% of the subjects used audio-visual aids in their EFL classes, while $65 \%$ do not use them. This result shows that the teachers do not have expertise in using audio-visual aids for teaching $E F L$, which the students find attractive and beneficial.

Discussion of the second question: Do you think that audio-visual aids are beneficial for teaching EFL classes?

Table (2): Do you think that audio-visual aids help teach EFL classes?

\begin{tabular}{|c|c|c|}
\hline Scale & No of respondents & Percentage (\%) \\
\hline Yes & 18 & $90 \%$ \\
\hline No & 02 & $10 \%$ \\
\hline Total & $\mathbf{2 0}$ & $\mathbf{1 0 0} \%$ \\
\hline
\end{tabular}

Table: 2 illustrates, 18 out of 20 teachers answered Yes, while 02 teachers answered No. In other words, 90\% of teachers believed that audio-visual aids were beneficial for teaching the English language; but only $10 \%$ found that it was not beneficial to use audio-visual aids in their EFL classes.

The result obviously reveals that a majority of the teachers find it beneficial to use audio-visual aids for teaching EFL in Kufrah secondary schools.

Discussion of the third question: Are you pleased with the use of audio-visual aids in your EFL classes?

Table (3): Are you pleased with the use of audio-visual aids in your EFL classes?

\begin{tabular}{|c|c|c|}
\hline Scale & No of respondents & Percentage (\%) \\
\hline Strongly satisfied & 06 & $70 \%$ \\
\hline Slightly satisfied & 14 & $00 \%$ \\
\hline Dissatisfied & 00 & $\mathbf{1 0 0} \%$ \\
\hline Total & $\mathbf{2 0}$ & $\mathbf{0 0}$ \\
\hline
\end{tabular}

Table 3 reveals that out of 20 teachers, 6 teachers were strongly satisfied, and 14 were slightly satisfied. That is, only $30 \%$ of teachers were found strongly satisfied with the use of audio-visual aids in their EFL classes, whereas $70 \%$ seemed to be slightly satisfactory in this respect.

The result shows that all the EFL teachers in Kufrah secondary schools are more or less satisfied with audio visual aids for their teaching. Nevertheless, most of the subjects (70\%) have slight satisfaction, which indicates the lack of teacher training, teacher motivation, and administrative support. 


\section{Discussion of the fourth question: Which EFL classes are more operative and stimulating to the student?}

Table (4): Which EFL classes are more operative and stimulating to the student?

\begin{tabular}{|c|c|c|}
\hline Scale & No of respondents & Percentage (\%) \\
\hline Classes with audio-visual aids & 18 & $10 \%$ \\
\hline Classes without audio-visual aids & 02 & $\mathbf{1 0 0} \%$ \\
\hline Total & $\mathbf{2 0}$ & $10 \%$ \\
\hline
\end{tabular}

Table 4 reveals that 18 out of 20 teachers ticked Classes with audio-visual aids and the remaining 02 teachers ticked Classes without audio-visual aids. That is, $90 \%$ of teachers supported that EFL classes with audio-visual aids were more operative and stimulating to their students, while only $10 \%$ opined that EFL classes without audio visual aids were more operative and stimulating.

Discussion of the fifth question: How is the performance of the students in the English classes without audio-visual aids?

Table (5): How is the performance of the students in the English classes without audio-visual aids?

\begin{tabular}{|c|c|c|}
\hline Scale & No of respondents & Percentage (\%) \\
\hline Strongly satisfied & 00 & $60 \%$ \\
\hline Slightly satisfied & 12 & $\mathbf{4 0 \%}$ \\
\hline Dissatisfied & $\mathbf{0 8}$ & $\mathbf{1 0 0} \%$ \\
\hline Total & $\mathbf{2 0}$ & \\
\hline
\end{tabular}

Table 5 demonstrates that 12 out of 20 teachers ticked Slightly satisfied, 08 teachers ticked Dissatisfied, and none ticked Strongly satisfied. That is, $60 \%$ of teachers were slightly satisfied with their students' performance in the classes without audio visual aids, while $40 \%$ were dissatisfied with their students' performance in the class with the same condition.

This result can be attributed to the fact that students' performance failed to reach the EFL teachers' expectations and the programme's objective due to audio-visual services' deficiency.

\section{Discussion of the sixth question: How is the learners' performance in the English classes with audio-visual aids?}

Table (6): How is the performance of the learners in the English classes with audio-visual aids?

\begin{tabular}{|c|c|c|}
\hline Scale & No of respondents & Percentage (\%) \\
\hline Strongly satisfied & 06 & $50 \%$ \\
\hline Slightly satisfied & 10 & $20 \%$ \\
\hline Dissatisfied & 04 & $\mathbf{1 0 0} \%$ \\
\hline Total & $\mathbf{2 0}$ & \\
\hline
\end{tabular}

Table 6 shows that out of 20 teachers, 6 were strongly satisfied, 10 Slightly satisfied, and 4 dissatisfied. In other words, 30\% of teachers were strongly satisfied with the performance of their students in the classes with audio visual aids, and $50 \%$ of teachers were slightly satisfied with their students' performance in the same situation; but $20 \%$ of teachers were dissatisfied with their students' performance in the classes with audio visual aids.

This result clearly shows that students' performance reaches the expectations of teachers and the objective of the programme due to the use of audio-visual aids for teaching EFL. 


\section{Student's questionnaire}

The student's questionnaire comprised six items relating to students' perspectives on audio-visual aids in English classes. The 80 students' answers to the questionnaire are presented as follows:

\section{Discussion of the first question: Does your teacher use audio-visual aids in your EFL classes?}

Table (7): Does your teacher use audio-visual aids in your EFL classes?

\begin{tabular}{|c|c|c|}
\hline Scale & No of respondents & Percentage (\%) \\
\hline Yes & 16 & $80 \%$ \\
\hline No & 64 & $\mathbf{1 0 0} \%$ \\
\hline Total & $\mathbf{8 0}$ & $\%$ \\
\hline
\end{tabular}

Table 7 shows that 16 out of 80 students responded Yes, while 64 students responded No. That is to say, 20\% of participants found that their teacher using audio-visual in their EFL classes, but $80 \%$ did not find their EFL teacher using audio visual aids.

Although the majority of students confess that their teachers do not use audio-visual aids in their EFL classes, it is in paradox with the teachers' perspectives since twenty percent teachers claim that they do not use audio-visual aids in their classes. Though, it is here evident that audio-visual aids are not used in most of the EFL classes at Kufrah secondary schools.

\section{Discussion of the second question: Do you think that audio-visual aids are beneficial for learning English language?}

Table (8): Do you think that audio-visual aids is beneficial for learning English language?

\begin{tabular}{|c|c|c|}
\hline Scale & No of respondents & Percentage (\%) \\
\hline Yes & 73 & $91.25 \%$ \\
\hline No & 07 & $8.75 \%$ \\
\hline Total & $\mathbf{8 0}$ & $\mathbf{1 0 0} \%$ \\
\hline
\end{tabular}

Table 8 demonstrates that 73 out of 80 students answered positively, whereas the rest negatively. That is, $91.25 \%$ of students thought that audio-visual aids were beneficial for learning English, but only $8.75 \%$ of students did not consider audio-visual aids to be beneficial.

The result is in a very close relationship with that related to teachers since the vast majority of students (91.25\%) and teachers (90\%) feel that audio visual aids are beneficial for teaching and learning EFL.

Discussion of the third question: Are you pleased with the use of audio-visual aids in the EFL classes?

Table (9): Are you satisfied with the use of audio-visual aids in the EFL classes?

\begin{tabular}{|c|c|c|}
\hline Scale & No of respondents & Percentage (\%) \\
\hline Strongly satisfied & 04 & $55 \%$ \\
\hline Slightly satisfied & 44 & $40 \%$ \\
\hline Dissatisfied & 32 & $\mathbf{1 0 0 \%}$ \\
\hline Total & $\mathbf{8 0}$ & $5 \%$ \\
\hline
\end{tabular}

Table: 9 reveals that out of 80 students, only 4 students marked Strongly satisfied, and 44 marked Slightly satisfied; but 32 students marked Dissatisfied. In other words, only $5 \%$ were satisfied, and $55 \%$ slightly satisfied with the use of audio visual aids in their EFL classes, whereas $40 \%$ of students were found to be dissatisfied. 
This result reveals, different all teachers being satisfied, a good number of students (40\%) are dissatisfied with the use of audio visual aids though the majority of students are more or less satisfied with the use of audio visual aids in their EFL classes.

Discussion of the fourth question: Which EFL classes are more operative and stimulating to you?

Table (10): Which EFL classes are more effective and interesting to you?

\begin{tabular}{|c|c|c|}
\hline Scale & No of respondents & Percentage (\%) \\
\hline Classes with audio-visual aids & 66 & $82.5 \%$ \\
\hline Classes without audio-visual aids & 14 & $17.5 \%$ \\
\hline Total & $\mathbf{8 0}$ & $\mathbf{1 0 0 \%}$ \\
\hline
\end{tabular}

Table: 10 shows that 66 out of 80 students marked Classes with audio-visual aids, and the remaining 14 students marked Classes without audio-visual aids. $82.5 \%$ students supported that EFL classes with audio-visual aids were more operative and stimulating, while only $17.5 \%$ opined that EFL classes without audio-visual aids were more operative and stimulating.

This result gives full support to the teachers' perspectives, and launches a fair use of audio-visual aids in the EFL classes in Kufrah secondary schools.

Discussion of the fifth question: How is your performance in the EFL classes without audio-visual aids?

Table (11): How is your performance in the EFL classes without audio-visual aids

\begin{tabular}{|c|c|c|}
\hline Scale & No of respondents & Percentage (\%) \\
\hline Strongly satisfied & 17 & $35 \%$ \\
\hline Slightly satisfied & 28 & $43.75 \%$ \\
\hline Dissatisfied & 35 & $\mathbf{1 0 0 \%}$ \\
\hline Total & $\mathbf{8 0}$ & \\
\hline
\end{tabular}

Table 11 demonstrates that 17 out of 80 students were strongly satisfied, 28 students slightly satisfied, and 35 weree dissatisfied. That is, $21.25 \%$ of students were strongly satisfied, and $35 \%$ were slightly satisfied with the students' performance in the EFL classes without audio-visual aids, while $43.75 \%$ were dissatisfied with the students' performance in the EFL classes with the same situation.

Although the majority of students are more or less satisfied with their performance in EFL classes without audio visual aids, a large number of students are in a very close relationship with dissatisfied teachers.

Discussion of the sixth question: How is your performance in the EFL classes with audio-visual aids?

Table (12): How is your English performance with audio-visual aids?

\begin{tabular}{|c|c|c|}
\hline Scale & No of respondents & Percentage (\%) \\
\hline Strongly satisfied & 24 & $47.5 \%$ \\
\hline Slightly satisfied & 38 & $22.5 \%$ \\
\hline Dissatisfied & 18 & $\mathbf{1 0 0 \%}$ \\
\hline Total & $\mathbf{8 0}$ & $\%$ \\
\hline
\end{tabular}

Table 12 shows that out of 80 students, 24 were strongly satisfied, 38 slightly satisfied, and 18 were Dissatisfied. That is to say, $30 \%$ of students were strongly satisfied with the students' performance in the EFL classes with audio-visual aids, and 47.5 
students were slightly satisfied with the students' performance in the same situation, but 22.5 students were dissatisfied with the students' performance in the EFL classes with audio visual aids.

\section{Conclusion and Implications}

The presentation and explanations of the results of the study, as mentioned above, lead to the following interpretations:

The first research question: Are audio-visual aids used in Kufrah secondary schools? It can be inferred that audio visual aids are less used in most EFL classes in Kufrah secondary schools.

The second research question: If yes, how much are they beneficial? It can be considered that audio visual aids in the EFL classes in Kufrah secondary schools are beneficial since the use of audio-visual aids makes teaching attractive and operative and promotes learning by stimulating and inspiring the learner and attracting his/her attention during the educational process.

The third question: What are EFL teachers' perspectives about using audio-visual aids? It was evident that the EFL teachers do not have sufficient training and motivation as well as sufficient audio-visual equipment and administrative support required for using audio visual aids in the EFL classes.

The fourth question: What are students' perspectives about using audio-visual visual aids? It is noticeable that the students find audio visual aids very beneficial for EFL learning but suffer from the deficiency of trained teachers, insufficient audio-visual facilities and restricted administrative support.

Therefore, it can concisely be inferred that the use of audio-visual aids in the EFL classes in Kufrah secondary schools is an addition, but it is seriously hampered by the deficiency of teacher training, the inadequacy of audio-visual equipment and material, and the indifference of the administration.

\subsection{Recommendations}

Based on the results mentioned above, the following recommendations were made:

a. Educational policy-makers should encourage the use of audio-visual aids by instilling them in the curriculum at all levels of education.

b. Both EFL students and teachers should get involved in their various roles in improvising and utilising audio-visual aids resources when necessary.

c. The teacher should have expertise and interest to use audio-visual aids in his/her EFL class to make his/her teaching effective and facilitate learning to a considerable extent.

d. Teachers should use audio-visual aids in EFL classes to facilitate maximum learning.

e. EFL teacher should maximally use audio-visual aids including audio-visual equipment and material, in every class to develop learner's oral communication skills encompassing speaking and listening.

f. There should be suitable audio-visual aids facilities which the learners can use any time to practice EFL skills and improve his/her linguistic as well as communicative ability.

\section{References}

[1] Ahmad, T. 2013. Audio-Visual Aids in Teaching http://dailykashmirimages.com. Retrieved on December 21st 2013.

[2] Anderson, L. (1994). Simultaneous interpretation: Contextual and translation aspects. Amsterdam: Benjamins.

[3] Cakir, I. (2006). The use of video as an audio-visual material in foreign language teaching classroom. Turkish Online Journal of Educational Technology-TOJET, 5(4), 67-72.

[4] Harmer, J. (2001). The practice of English language teaching. England: Longman. Jain P. Educational Technology, Moujpur Publication, Delhi

[5] Keller, J., \& Suzuki, K. (2004). Learner motivation and e-learning design: A mult nationally validated process. Journal of educational Media, 29(3), 229-239.

[6] Kishor, N. (2003). Educational technology. Abhishek publication..

[7] Madhuri, J. N. (2013). Use of Audio Visual Aids in Teaching and Speaking. Research Journal of English Language and Literature, 1(3), 108-122.

[8] Mohanty, J. (2001). Educational technology. Deep and Deep Publications.

[9] Riddel, D. (2001). Teach yourself: Teaching English as a foreign language. London: Hodder Headline Ltd.

[10] Rather, A. R. (2004). Essentials Instructional Technology, published by Darya gaj New Delhi.

[11] Richards, J. C., \& Renandya, W. A. (2002). Methodology in language teaching: An anthology of current practice: Cambridge university press.

[12] Richards, Jack C. and Rodgers, T. S. (2002). Approaches and Methods in Language Teaching: a Description and analysis. Cambridge: Cambridge University Press.

[13] Subartha, P. (2012). The audio-visual aids in English teaching. In National Conference on Developing Scenario in Applied Science and Communicative English. 